\title{
Inhibition Behaviour of Some Isonicotinic Acid Hydrazides on the Corrosion of Mild Steel in Hydrochloric Acid Solution
}

\author{
M. P. Chakravarthy and K. N. Mohana \\ Department of Studies in Chemistry, University of Mysore, Manasagangothri, Mysore 570 006, India \\ Correspondence should be addressed to M. P. Chakravarthy; chakku01@gmail.com
}

Received 19 July 2013; Accepted 26 September 2013

Academic Editor: Flavio Deflorian

Copyright (c) 2013 M. P. Chakravarthy and K. N. Mohana. This is an open access article distributed under the Creative Commons Attribution License, which permits unrestricted use, distribution, and reproduction in any medium, provided the original work is properly cited.

\begin{abstract}
New corrosion inhibitors, namely, isonicotinic acid (1H-indol-3-yl-methylene)hydrazide (INIMH) and isonicotinic acid (1Hpyrrol-2-yl-methylene)hydrazide (INPMH), have been synthesized, and their inhibitive characteristics for the corrosion of mild steel in $0.5 \mathrm{M} \mathrm{HCl}$ were investigated by mass loss and electrochemical techniques. The structures of the synthesized compounds were confirmed using spectral studies. Potentiodynamic polarization studies revealed that the investigated inhibitors are of mixed type. Various thermodynamic parameters were evaluated. Langmuir adsorption isotherm was found to be the best description for both inhibitors. FTIR spectra, energy dispersive X-ray spectroscopy (EDX), and scanning electron microscopy (SEM) were performed to characterize the passive film on the metal surface.
\end{abstract}

\section{Introduction}

Mild steel is the most important engineering material particularly for structural, instrumental, industrial, and automobile applications. Corrosion problem occurs in these industries and can cause disastrous damage to metal and alloy structures causing economic consequences in terms of repair, replacement, and product losses. Pickling is a treatment on metallic surfaces in order to remove tightly adherent oxide films, stains, rust, or scale resulting from hot forming, heat treating, welding, and other high temperature operations [1]. The two acids commonly used in pickling are hydrochloric acid or sulphuric acid or it may be a combination of acids and may also contain nitric or hydrofluoric acids. Once the acid is rinsed out, the freshly cleaned steel will be very prone to oxidation (corrode) unless we apply a corrosion inhibitor of some type [2]. Therefore, a wide variety of corrosion inhibitors ranging from rare earth elements $[3,4]$ to organic compounds [5-8] have been used. The use of inhibitors is one of the practical methods for preventing corrosion of mild steel especially in acid media [9]. Inhibitors protect the metal by adsorbing on the surface and retard metal corrosion in aggressive environment. Selection of an appropriate inhibitor for specific environment and metal is of great importance.

Generally, the heterocyclic organic compounds having higher basicity and electron density on the heteroatoms like oxygen, nitrogen, and sulphur have a tendency to resist corrosion $[10,11]$. It has been known that efficient inhibitors should possess plentiful pi-electrons and unshared electron pairs on either nitrogen atoms or sulfur atoms of the inhibitors to the d-orbital of iron. The adsorption characteristics of organic molecules are also affected by sizes, electron density at the donor atoms, and orbital character of donating electrons [12-16]. Organic compounds containing functional electronegative groups, pi-electron in triple or conjugated double bonds, and presence of aromatic rings in their structure are the major adsorption centers and are usually good inhibitors [17]. Several nitrogen, oxygen, and sulphur containing heterocyclic compounds such as benzoxazole derivatives [18], thiazole derivatives [19], benzothiazole derivatives [20], thiourea derivatives [21], imidazole derivatives [22],triazines [23], pyrazole derivatives [24], thiophene derivatives [25], and quinoxaline derivatives [26] have been reported as anticorrosion substances. 
<smiles></smiles>

FIGURE 1: Synthetic schemes of INIMH and INPMH.

The review of the literature revealed that the use of isonicotinic acid derivatives as corrosion inhibitors is scanty. In view of the above, the present work is aimed to study the corrosion inhibition efficiencies of the newly synthesized isonicotinic acid (1H-indol-3-yl-methylene)hydrazide (INIMH) and isonicotinic acid (1H-pyrrol-2-yl-methylene)hydrazide (INPMH) on mild steel (MS) in $0.5 \mathrm{M} \mathrm{HCl}$ using mass loss and electrochemical techniques. The experimental findings were discussed with various activation and adsorption thermodynamic parameters. Further, the protective film formed on the metal surface was characterized by FTIR, EDX, and SEM.

\section{Experimental}

2.1. Materials. MS specimens used in the present study have the following chemical compositions (in wt \%): C 0.051; Mn 0.179; Si 0.006; Cr 0.051; Ni 0.05; Mo 0.013; Ti 0.004; Al 0.103; Cu 0.050; Sn 0.004; B 0.00105; Co 0.017; Nb 0.012; Pb 0.001; and the remainder iron. For all experiments, square type mild steel specimens of dimension $2 \mathrm{~cm} \times 2 \mathrm{~cm} \times 0.1 \mathrm{~cm}$ were used. The specimens were mechanically polished with different grades $\mathrm{SiC}$ (200-600) emery papers, degreased with benzene, washed with doubly distilled water, and finally dried. All the solvents and chemicals used were of analytical reagent grade and used as such. Doubly distilled water was used in the preparation of the various concentrations of test solutions.

2.2. Synthesis of Inhibitors. INIMH was synthesized by dissolving $2.07 \mathrm{~g}(15 \mathrm{mmol})$ of isoniazide $\left(\mathrm{C}_{6} \mathrm{H}_{7} \mathrm{~N}_{3} \mathrm{O}\right)$ in $15 \mathrm{~mL}$ of ethanol in a round bottom flask. To this $2.17 \mathrm{~g}(15 \mathrm{mmol})$ of indole-3-carboxaldehyde $\left(\mathrm{C}_{9} \mathrm{H}_{7} \mathrm{NO}\right)$ in $15 \mathrm{~mL}$ ethanol was mixed and refluxed for $6 \mathrm{hrs}$ at room temperature in presence of glacial acetic acid and then the solution was concentrated using rotor vaporizer and kept for dry in vacuum. INPMH was synthesized by dissolving $1.37 \mathrm{~g}(10 \mathrm{mmol})$ of isoniazide in $15 \mathrm{~mL}$ of ethanol in a round bottom flask. To this a $0.95 \mathrm{~g}(10 \mathrm{mmol})$ of the pyrrole-2-carboxaldehyde $\left(\mathrm{C}_{5} \mathrm{H}_{5} \mathrm{NO}\right)$ dissolved in $15 \mathrm{~mL}$ of ethanol was added and refluxed for 6 hrs with stirring at room temperature in presence of glacial acetic acid. Then the solution was concentrated using rotor vaporizer and kept for dry in vacuum, and the product obtained was collected. The synthetic scheme of INIMH and INPMH is shown in Figure 1.

The chemical structures of the compounds are characterized by FTIR and ${ }^{1} \mathrm{H}-\mathrm{NMR}$ spectral studies. INIMH $\left(\mathrm{C}_{15} \mathrm{H}_{12} \mathrm{~N}_{4} \mathrm{O}\right.$, Mol. Wt. 264.28): yield: $91 \%$, melting range (M. R, $\left.{ }^{\circ} \mathrm{C}\right): 138-142$. FTIR $\left(\mathrm{KBr}, \mathrm{cm}^{-1}\right): 1599(\mathrm{~N}=\mathrm{C}), 1654$ $(\mathrm{NHC}=\mathrm{O})$, and $1462(\mathrm{NH}) .{ }^{1} \mathrm{H}-\mathrm{NMR}(400.15 \mathrm{MHz}, \mathrm{DMSO}-$ $\mathrm{d}_{6}$ ) $\delta$ ppm: $7.14-7.23$ (m, 2H, indole ring), 7.45 (s, $1 \mathrm{H}, \mathrm{NH}$ of indole), 7.88 ( $\mathrm{s}, 1 \mathrm{H}$, indole ring), 7.92-7.94 (d, $J=4.92 \mathrm{~Hz}, 2 \mathrm{H}$, pyridine ring), $8.28(\mathrm{~d}, 1 \mathrm{H}, J=7.64 \mathrm{~Hz}), 8.63(\mathrm{~s}, 1 \mathrm{H}, \mathrm{CH}$ of $\mathrm{N}=\mathrm{CH}), 8.85(\mathrm{dd}, J=4.96,16.24 \mathrm{~Hz}, 2 \mathrm{H}), 11.66(\mathrm{~s}, 1 \mathrm{H}, \mathrm{NH}$ of indole), and 11.81 (s, 1H, NH of hydrazide). MS, m/z: 265 $(\mathrm{M}+1)$. Elemental analysis found (calculated) for $\mathrm{C}_{15} \mathrm{H}_{12} \mathrm{~N}_{4} \mathrm{O}$ (\%): C, 68.09 (68.17): H, 4.47 (4.58): N, 21.15 (21.20), O, 5.99 (6.05).

INPMH $\left(\mathrm{C}_{11} \mathrm{H}_{10} \mathrm{~N}_{4} \mathrm{O}\right.$, Mol. Wt. 214.22): yield: $87 \%$, melting range $\left(\mathrm{M} . \mathrm{R},{ }^{\circ} \mathrm{C}\right): 110-112$. FTIR $\left(\mathrm{KBr}, \mathrm{cm}^{-1}\right): 1603(\mathrm{~N}=\mathrm{C})$, $1648(\mathrm{NHC}=\mathrm{O})$, and $1457(\mathrm{NH}) .{ }^{1} \mathrm{H}-\mathrm{NMR}(400.15 \mathrm{MHz}$, DMSO- $\left.\mathrm{d}_{6}\right) \delta$ ppm: $6.15(\mathrm{~s}, 1 \mathrm{H}$, pyrrole ring), $6.53(\mathrm{~s}, 1 \mathrm{H}$, pyrrole ring), 6.93 (s, $1 \mathrm{H}$, pyrrole ring), $7.82(\mathrm{~d}, J=6.00 \mathrm{~Hz}$, $2 \mathrm{H}$, pyridine ring), $8.28(\mathrm{~s}, 1 \mathrm{H}, \mathrm{CH}$ of $\mathrm{N}=\mathrm{CH}), 8.77(\mathrm{~d}, J=$ $5.88 \mathrm{~Hz}, 2 \mathrm{H}$, pyridine ring), $11.60(\mathrm{~s}, 1 \mathrm{H}, \mathrm{NH}$ of pyrrole), and 11.75 (s, 1H, NH of hydrazide). MS, m/z: $215(\mathrm{M}+1)$. Elemental analysis found (calculated) for $\mathrm{C}_{11} \mathrm{H}_{10} \mathrm{~N}_{4} \mathrm{O}(\%)$ : C, 61.54 (61.67): H, 4.69 (4.71): N, 26.02 (26.15), O, 7.33 (7.47). Melting range was determined by Veego Melting Point VMP III apparatus. FTIR spectra were recorded using a Jasco FTIR 4100 double beam spectrophotometer. ${ }^{1} \mathrm{H}$-NMR spectra were recorded on Bruker DRX-500 spectrometer at $400 \mathrm{MHz}$ using DMSO- $\mathrm{d}_{6}$ as solvent and TMS as an internal standard. Mass spectral data were obtained by LC/MSD Trap XCT. Elemental analyses were recorded on VarioMICRO superuser V1.3.2 Elementar. 
2.3. Mass Loss Measurements. Mass loss measurements were carried out by weighing cleaned and dried MS specimens before and after immersion in $0.5 \mathrm{M} \mathrm{HCl}$ solutions for one to five hours in the absence and presence of various concentrations of INIMH and INPMH at different temperatures (30$60^{\circ} \mathrm{C}$ ). Triplicate experiments were performed in each case, and the mean value of the mass loss was noted. Corrosion rate (CR) in $\mathrm{mg} \mathrm{cm}^{-2} \mathrm{~h}^{-1}$ and inhibition efficiency IE (\%) were calculated using the following equations:

$$
\mathrm{CR}=\frac{\Delta W}{S t},
$$

where $\Delta W$ is the weight loss, $S$ is the surface area of the specimen and $t$ is immersion time.

$$
\operatorname{IE}(\%)=\frac{(\mathrm{CR})_{a}-(\mathrm{CR})_{p}}{(\mathrm{CR})_{a}} \times 100,
$$

where $(\mathrm{CR})_{a}$ and $(\mathrm{CR})_{p}$ are the corrosion rates in the absence, and presence of inhibitor, respectively.

2.4. Potentiodynamic Polarization Measurements. The potentiodynamic polarization studies were carried out with MS specimen with an exposed area of $1 \mathrm{~cm}^{2}$. A conventional three-electrode cell consisting of MS as working electrode, platinum foil as counter electrode, and saturated $\mathrm{Ag}-\mathrm{AgCl}$ electrode as reference electrode was used. Potentiodynamic polarization studies were carried out using $\mathrm{CH}$-instrument (modelCHI660D). The IE (\%) was calculated from corrosion currents determined from the Tafel extrapolation plot method using the following relation:

$$
\operatorname{IE}(\%)=\frac{\left(I_{\text {corr }}\right)_{a}-\left(I_{\text {corr }}\right)_{p}}{\left(I_{\text {corr }}\right)_{a}} \times 100,
$$

where $\left(I_{\text {corr }}\right)_{a}$ and $\left(I_{\text {corr }}\right)_{p}$ are the corrosion current density $\left(\mu \mathrm{A} \mathrm{cm}{ }^{-2}\right)$ in the absence and presence of the inhibitor, respectively.

2.5. Electrochemical Impedance Spectroscopy. Electrochemical impedance measurements were carried out using the same $\mathrm{CH}$-instrument. The electrochemical impedance spectroscopy (EIS) data were taken in the frequency range $10 \mathrm{kHz}$ to $100 \mathrm{mHz}$. The double layer capacitance $\left(C_{d l}\right)$ and the polarization resistance $\left(R_{p}\right)$ were determined from Nyquist plots [27]. The IE (\%) was calculated from $R_{p}$ values using the following expression:

$$
\operatorname{IE}(\%)=\frac{\left(1 /\left(R_{p}\right)_{a}\right)-\left(1 /\left(R_{p}\right)_{p}\right)}{1 /\left(R_{p}\right)_{a}} \times 100
$$

where $\left(R_{p}\right)_{a}$ and $\left(R_{p}\right)_{p}$ are polarization resistances in the absence and presence of inhibitor, respectively.

2.6. FTIR, EDX, and SEM Studies. The MS specimens were immersed in $0.5 \mathrm{M} \mathrm{HCl}$ in the presence of inhibitors
$(500 \mathrm{ppm})$ for a period of $5 \mathrm{hrs}$. Then the specimens were taken out and dried. The surface adhered film was scratched carefully, and its IR spectra were recorded using a Jasco FTIR 4100 double beam spectrometer. The surface feature of the MS specimens in the absence and presence of inhibitors was studied by energy dispersive X-ray spectroscopy (EDX) and scanning electron microscope (model JSM-5800).

\section{Results and Discussion}

3.1. Mass Loss Studies. The CR and IE (\%) in the absence and presence of various concentrations of INIMH and INPMH in $0.5 \mathrm{M} \mathrm{HCl}$ solution and at different temperatures are presented in Table 1. The mass loss was found to be decreased, and the IE (\%) increased with increase in concentration of isonicotinic acid hydrazides. Beyond $500 \mathrm{ppm}$, there is no significant increase in percentage IE (\%). There is no appreciable increase in the IE (\%) after $1 \mathrm{hr}$ of immersion time; this is due to desorption of the inhibitor molecule from metal surface with increasing immersion time and instability of inhibitor film on the metal surface $[28,29]$. It was found that INIMH showed slightly higher IE (\%) when compared with that of INPMH.

3.2. Effect of Temperature. The effect of temperature on CR and IE (\%) was studied in $0.5 \mathrm{M} \mathrm{HCl}$ in the temperature range of $30-60^{\circ} \mathrm{C}$ in the absence and presence of different concentrations of inhibitors (Table 1). It was found that the IE (\%) decreased with increasing temperature from $30-60^{\circ} \mathrm{C}$. This proves that the inhibition occurs through the adsorption of the inhibitors on the metal surface, and description is aided by an increase in temperature. The activation parameters for the corrosion process were calculated from the Arrhenius type plot according to the following equation:

$$
\mathrm{CR}=k \exp ^{-E_{a} / R T}
$$

where $E_{a}$ is the activation energy, $k$ is the frequency factor, $T$ is the absolute temperature, and $R$ is the universal gas constant. The values of $E_{a}$ for $\mathrm{MS}$ in $0.5 \mathrm{M} \mathrm{HCl}$ without and with various concentrations of inhibitors are obtained from the slope of the plot of log CR versus $1 / T$ (Figure 2) and are shown in Table 2. It was found that $E_{a}$ values for inhibited systems are higher than for the uninhibited system (Table 2). This increase in the activation energy decreases the dissolution of metal [30]. With increase in temperature there was an appreciable decrease in the adsorption of the inhibitors on the metal surface, and a corresponding rise in the corrosion rate occurred [31].

Alternative Arrhenius plots of $\log \mathrm{CR} / T$ versus $1 / T$ (Figure 3) for MS dissolution in $0.5 \mathrm{M} \mathrm{HCl}$ medium in the absence and presence of different concentrations of INIMH and INPMH were used to calculate the values of activation thermodynamic parameters such as enthalpy of activation $\left(\Delta H_{a}\right)$ and entropy of activation $\left(\Delta S_{a}\right)$ using the following relation:

$$
\mathrm{CR}=\frac{R T}{N h} \exp \left(\frac{\Delta S_{a}}{R}\right) \exp \left(\frac{-\Delta H_{a}}{R T}\right),
$$


TABLE 1: CR and IE (\%) obtained from mass loss measurements of MS in $0.5 \mathrm{M} \mathrm{HCl}$ solution containing various concentrations of INIMH and INPMH at different temperatures.

\begin{tabular}{|c|c|c|c|c|c|}
\hline \multirow{2}{*}{$T\left({ }^{\circ} \mathrm{C}\right)$} & \multirow{2}{*}{ Concentration (ppm) } & \multicolumn{2}{|c|}{ INIMH } & \multicolumn{2}{|c|}{ INPMH } \\
\hline & & $\mathrm{CR}\left(\mathrm{mg} \mathrm{cm}^{-2} \mathrm{~h}^{-1}\right)$ & IE (\%) & $\mathrm{CR}\left(\mathrm{mg} \mathrm{cm}^{-2} \mathrm{~h}^{-1}\right)$ & IE (\%) \\
\hline \multirow{5}{*}{30} & Blank & 0.7200 & - & 0.7200 & - \\
\hline & 200 & 0.2296 & 68.16 & 0.2367 & 67.19 \\
\hline & 300 & 0.1875 & 74.00 & 0.1947 & 73.01 \\
\hline & 400 & 0.1288 & 82.14 & 0.1359 & 81.15 \\
\hline & 500 & 0.0998 & 86.16 & 0.1069 & 85.17 \\
\hline \multirow{5}{*}{40} & Blank & 0.9490 & - & 0.9490 & - \\
\hline & 200 & 0.3202 & 66.24 & 0.3296 & 65.25 \\
\hline & 300 & 0.2814 & 70.33 & 0.2909 & 69.33 \\
\hline & 400 & 0.1895 & 80.02 & 0.1986 & 79.05 \\
\hline & 500 & 0.1573 & 83.41 & 0.1672 & 82.37 \\
\hline \multirow{5}{*}{50} & Blank & 1.1520 & - & 1.1520 & - \\
\hline & 200 & 0.4091 & 64.49 & 0.4214 & 63.41 \\
\hline & 300 & 0.3562 & 69.07 & 0.3669 & 68.15 \\
\hline & 400 & 0.2474 & 78.52 & 0.2591 & 77.50 \\
\hline & 500 & 0.2001 & 82.62 & 0.2107 & 81.70 \\
\hline \multirow{5}{*}{60} & Blank & 1.4350 & - & 1.4350 & - \\
\hline & 200 & 0.5376 & 62.54 & 0.5514 & 61.58 \\
\hline & 300 & 0.4555 & 68.27 & 0.4693 & 67.30 \\
\hline & 400 & 0.3418 & 76.18 & 0.3565 & 75.16 \\
\hline & 500 & 0.2745 & 80.87 & 0.2891 & 79.85 \\
\hline
\end{tabular}

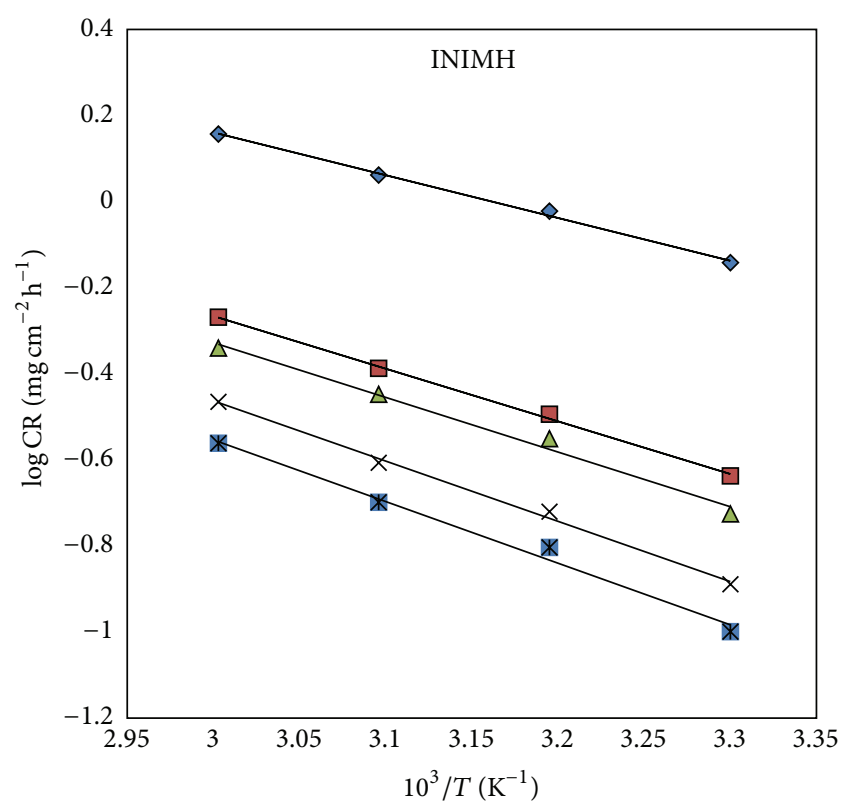

$\diamond$ Blank

$\triangle 300 \mathrm{ppm}$

* $500 \mathrm{ppm}$

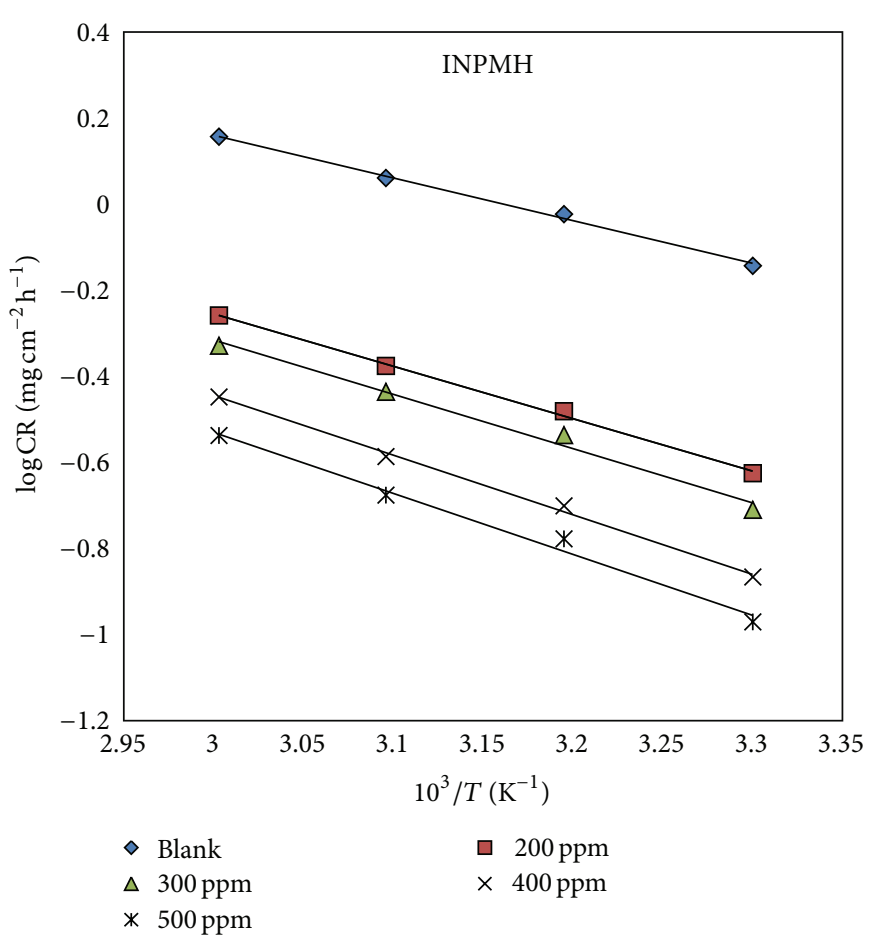

(b)

(a)

$\square \quad 200 \mathrm{ppm}$
$\times \quad 400 \mathrm{ppm}$

FIgure 2: Plots of $\log$ CR versus $1 / T$ for INIMH and INPMH. 
TABLE 2: Activation parameters for MS in $0.5 \mathrm{M} \mathrm{HCl}$ medium in the absence and presence of INIMH and INPMH at $500 \mathrm{ppm}$.

\begin{tabular}{lcccccc}
\hline Inhibitor & Concentration $(\mathrm{ppm})$ & $E_{a}\left(\mathrm{~kJ} \mathrm{~mol}^{-1}\right)$ & $k\left(\mathrm{mg} \mathrm{cm}^{-2} \mathrm{~h}^{-1}\right)$ & $\Delta H_{a}\left(\mathrm{~kJ} \mathrm{~mol}^{-1}\right)$ & $\Delta H_{a}=E_{a}-R T\left(\mathrm{~kJ} \mathrm{~mol}^{-1}\right)$ & $\Delta S_{a}\left(\mathrm{~J} \mathrm{~mol}^{-1} \mathrm{~K}^{-1}\right)$ \\
\hline Blank & 0 & 19.003 & 1374.041 & 16.365 & 16.484 & -197.574 \\
\hline \multirow{3}{*}{ INIMH } & 200 & 23.455 & 2570.396 & 20.813 & 20.936 & -188.498 \\
& 300 & 24.355 & 3076.096 & 21.713 & 21.836 & -187.005 \\
& 400 & 26.748 & 5357.966 & 24.106 & 24.229 & -182.391 \\
\hline \multirow{3}{*}{ INPMH } & 500 & 27.457 & 5610.479 & 24.815 & 20.763 & -182.027 \\
& 200 & 23.282 & 2483.133 & 20.659 & 21.568 & -188.785 \\
& 300 & 24.087 & 2890.679 & 21.464 & 23.999 & -187.522 \\
& 400 & 26.519 & 5128.613 & 23.876 & 24.574 & -182.754 \\
\hline
\end{tabular}

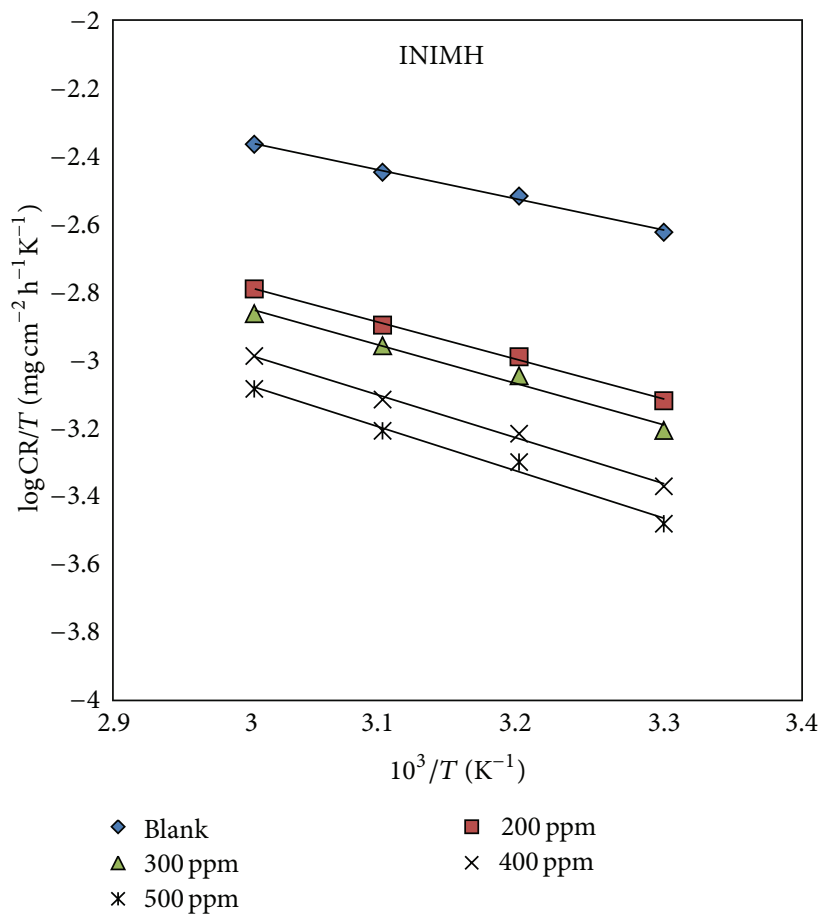

(a)

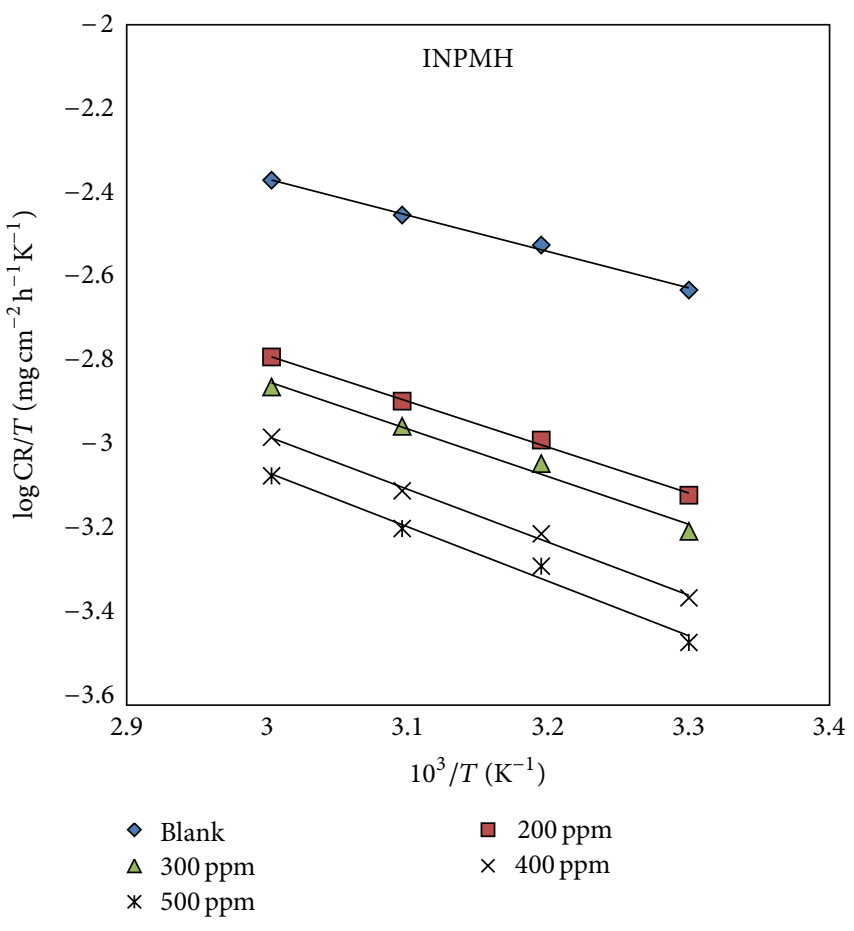

(b)

FIGURE 3: Alternative Arrhenius plots for MS dissolution in $0.5 \mathrm{M} \mathrm{HCl}$ medium in the absence and presence of INIMH and INPMH.

where $R$ is the universal gas constant, $T$ is the absolute temperature, $N$ is the Avogadro's number, and $h$ is Planks constant. The values of $\Delta H_{a}$ and $\Delta S_{a}$ were obtained from the slope and intercept of the previous plot. The obtained $\Delta H_{a}$ values are in good agreement with the calculated $\Delta H_{a}$ from the equation

$$
\Delta H_{a}=E_{a}-R T
$$

The positive values of enthalpy of activation in the absence and presence of inhibitors indicate an endothermic nature of MS dissolution process [32], and the negative entropy of activation values represents association rather than dissociation of inhibitor indicating decrease in the system disorder due to the adsorption of inhibitor molecule on the MS surface [3335].

3.3. Adsorption Isotherm. The adsorption of inhibitor molecules from aqueous solution is a quasisubstitution process and was found to be highly $\mathrm{pH}$ dependent [36]. The surface protection of MS depends upon how the inhibitor molecule will be adsorbed on the metal surface and also ionization and polarization of molecule [37]. The degree of surface coverage $(\theta)$ as function of concentration $(C)$ of the inhibitor was studied graphically by fitting it to various adsorption isotherms to find the best adsorption isotherm. Langmuir adsorption isotherm was found to be the best description for both INIMH and INPMH on MS in $0.5 \mathrm{M}$ 


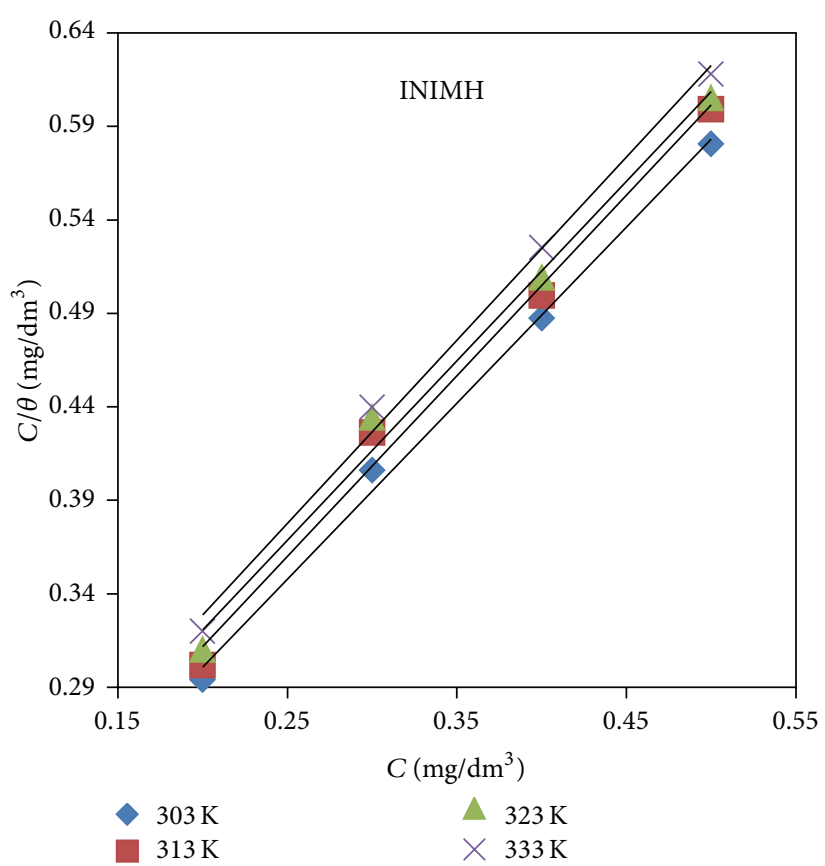

(a)

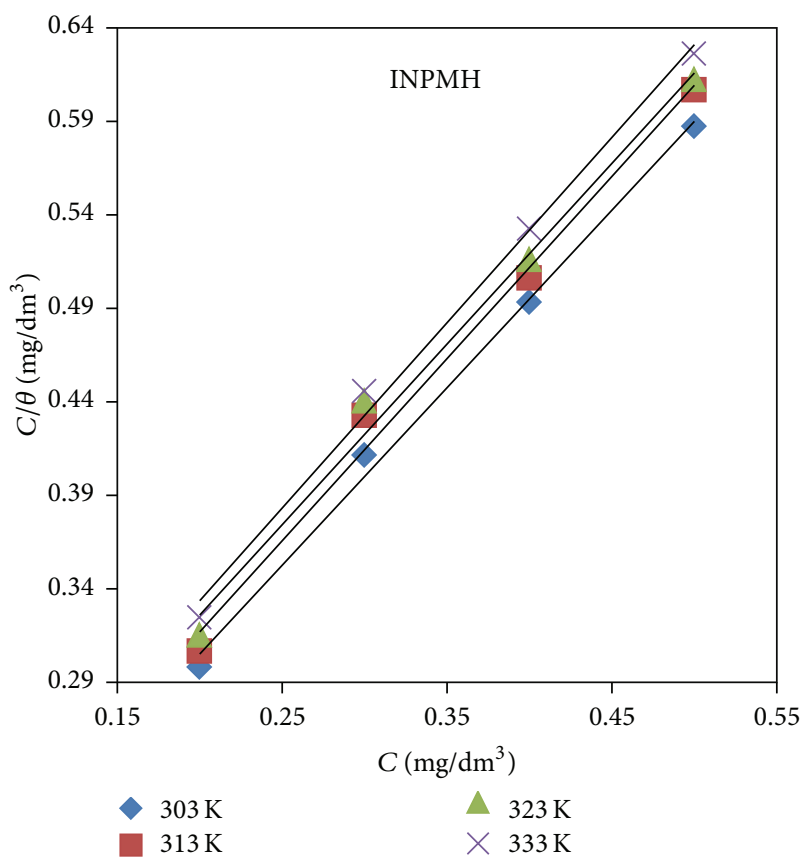

(b)

FIGURE 4: Langmuir's adsorption isotherm plots for the adsorption of INIMH and INPMH in $0.5 \mathrm{M} \mathrm{HCl}$ on the MS surface at different temperatures.

$\mathrm{HCl}$ medium. According to this adsorption isotherm, $\theta$ is related to the inhibitor concentration, $C$, and adsorption equilibrium constant, $K_{\text {ads }}$, through the following expression:

$$
\frac{c}{\theta}=\frac{1}{K_{\mathrm{ads}}}+C
$$

The plot of $C / \theta$ versus $C$ gave straight lines (Figure 4 ) with regression close to unity confirming that the adsorption of INIMH and INPMH on MS surface in $0.5 \mathrm{M} \mathrm{HCl}$ medium obeys the Langmuir adsorption isotherm. The free energy of adsorption was calculated using the following relations:

$$
\Delta G_{\mathrm{ads}}^{\circ}=-2.303 R T \log 55.5 K_{\mathrm{ads}},
$$

where $R$ is the universal gas constant, $T$ is the absolute temperature, $K_{\text {ads }}$ is the equilibrium constant for adsorption process, and 55.5 is the molar concentration of water in solution $\left(\mathrm{mol} \mathrm{L}^{-1}\right)$. The other adsorption thermodynamic parameters such as enthalpy of adsorption $\left(\Delta H_{\text {ads }}^{\circ}\right)$ and entropy of adsorption $\left(\Delta S_{\text {ads }}^{\circ}\right)$ were obtained from the slope and intercept of the plot of $\log K_{\mathrm{ads}}$ versus $1 / T$ (Figure 5) using

$$
\log K_{\mathrm{ads}}=\frac{1}{2.303}\left(-\frac{\Delta H_{\mathrm{ads}}^{\circ}}{R T}\right)+\left(\frac{\Delta S_{\mathrm{ads}}^{\circ}}{R}\right) .
$$

The calculated values of $K_{\mathrm{ads}}, \Delta H_{\mathrm{ads}}^{\circ}, \Delta G_{\mathrm{ads}}^{\circ}$, and $\Delta S_{\mathrm{ads}}^{\circ}$ over the temperature range $30-60^{\circ} \mathrm{C}$ are recorded in Table 3 . The negative values of $\Delta G_{\mathrm{ads}}^{\circ}$ and positive value of $\Delta H_{\mathrm{ads}}^{\circ}$ indicate the spontaneous adsorption of inhibitor on the surface of MS $[38,39]$. In the present study, $\Delta \mathrm{G}_{\mathrm{ads}}^{\circ}$ values

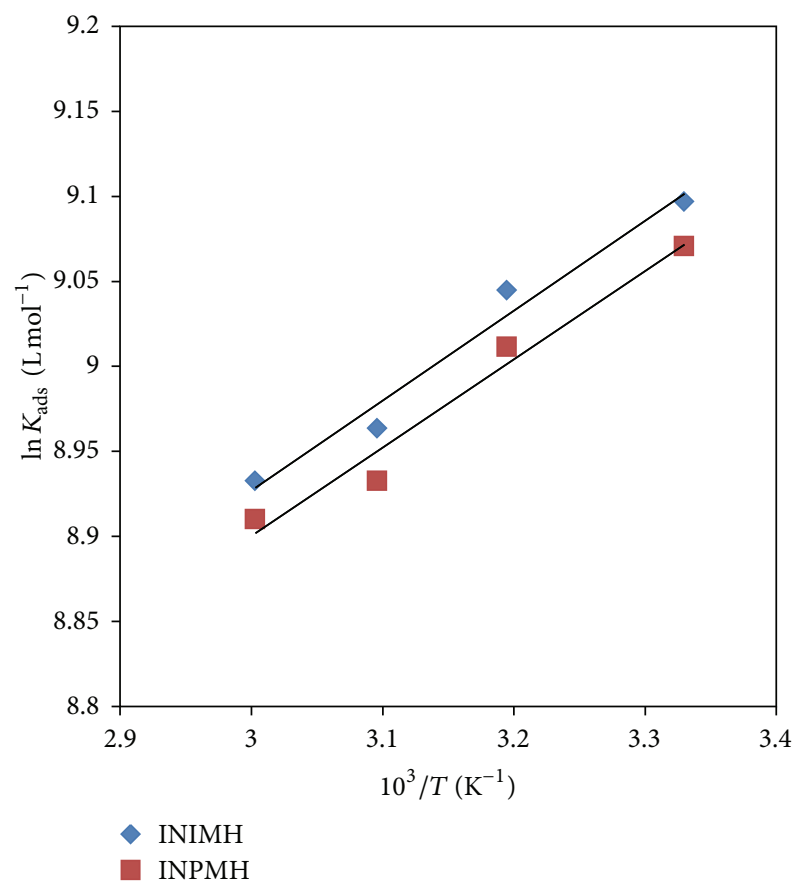

Figure 5: $\ln K_{\text {ads }}$ versus $1 / T$ plots of INIMH and INPMH.

for INIMH and INPMH are found to be in the ranges -33.04 to -35.85 and -32.97 to $-35.79 \mathrm{~kJ} \mathrm{~mol}^{-1}$, respectively, indicating adsorption process involving both physisorption and chemisorption [40-42]. 
TABLE 3: Thermodynamic parameters for adsorption of INIMH and INPMH on MS in $0.5 \mathrm{M} \mathrm{HCl}$ at different temperatures.

\begin{tabular}{|c|c|c|c|c|c|c|}
\hline Inhibitor & $T\left({ }^{\circ} \mathrm{C}\right)$ & $R^{2}$ & $K_{\text {ads }}\left(\mathrm{L} \mathrm{mol}^{-1}\right)$ & $\Delta G_{\mathrm{ads}}^{\circ}\left(\mathrm{kJ} \mathrm{mol}^{-1}\right)$ & $\Delta H_{\mathrm{ads}}^{\circ}\left(\mathrm{kJ} \mathrm{mol}^{-1}\right)$ & $\Delta S_{\mathrm{ads}}^{\circ}\left(\mathrm{J} \mathrm{mol}^{-1} \mathrm{~K}^{-1}\right)$ \\
\hline \multirow{4}{*}{ INIMH } & 30 & 0.995 & 8928.57 & -33.04 & \multirow{4}{*}{0.529} & \multirow{4}{*}{7.339} \\
\hline & 40 & 0.990 & 8474.57 & -33.99 & & \\
\hline & 50 & 0.990 & 7812.50 & -34.86 & & \\
\hline & 60 & 0.994 & 7575.76 & -35.85 & & \\
\hline \multirow{4}{*}{ INPMH } & 30 & 0.995 & 8695.65 & -32.97 & \multirow{4}{*}{0.518} & \multirow{4}{*}{7.344} \\
\hline & 40 & 0.990 & 8196.72 & -33.91 & & \\
\hline & 50 & 0.990 & 7575.75 & -34.78 & & \\
\hline & 60 & 0.994 & 7407.40 & -35.79 & & \\
\hline
\end{tabular}

3.4. IR Spectral Studies. FTIR spectra were recorded to understand the interaction of inhibitor molecules with the metal surface. Figures 6(a) and 7(a) show the IR spectra of pure INIMH and INPMH, and Figures 6(b) and 7(b) represent the spectra of the scratched samples obtained from the metal surfaces after corrosion experiments. It was found that peaks in the spectrum of pure compounds were changed in the spectrum of scratched samples. The azomethine group stretching frequency for pure INIMH and INPMH was found to be at $1599 \mathrm{~cm}^{-1}$ and $1603 \mathrm{~cm}^{-1}$, and amide carbonyl stretching frequency was observed at 1654 and $1648 \mathrm{~cm}^{-1}$, respectively. In the IR spectra of scrapped samples (Figure 8), the stretching frequencies of the azomethine group and amide carbonyl group were found to be disappearing in the case of INPMH, but slightly at lower frequency in the case of INIMH. These observations clearly indicate that the azomethine group and amide carbonyl group of INIMH and INPMH are involved in the complex formation with the metal. The $-\mathrm{NH}$ stretching frequencies of amide group were observed at $3182 \mathrm{~cm}^{-1}$ and $3200 \mathrm{~cm}^{-1}$ for INIMH and INPMH, respectively. The $-\mathrm{CH}$ stretching frequencies were observed at $2917 \mathrm{~cm}^{-1}$ and $2924 \mathrm{~cm}^{-1}$. The $-\mathrm{NH}$ stretching for indole ring in INIMH was observed at $1463 \mathrm{~cm}^{-1}$ and $-\mathrm{NH}$ stretching frequency for pyrrole ring in INPMH observed at $1457 \mathrm{~cm}^{-1}$.

3.5. Potentiodynamic Polarization Studies. Polarization curves for $\mathrm{MS}$ in $0.5 \mathrm{M} \mathrm{HCl}$ in the absence and presence of different concentrations of INIMH and INPMH at $30^{\circ} \mathrm{C}$ are shown in Figures 9(a) and 9(b). It has been reported [43, 44] that a compound can be classified as an anodic or a cathodic type inhibitor when the difference in $E_{\text {corr }}$ is greater than $85 \mathrm{mV}$ with reference to blank, otherwise inhibitor is treated as mixed type. In the present study, maximum displacement in $E_{\text {corr }}$ values is $71 \mathrm{mV}$ and $52 \mathrm{mV}$ for INIMH and INPMH, respectively, indicating that they are of mixed type [45].

In both cases, the addition of inhibitors reduces both anodic and cathodic currents. Various corrosion parameters such as corrosion current density $\left(i_{\text {corr }}\right)$, corrosion potential $\left(E_{\text {corr }}\right)$, corrosion rate, and IE (\%) are given in Table 4 . It is evident that IE (\%) increases with inhibitor concentration. The protection action of INIMH and INPMH can be attributed to the electron density of the azomethine $(-\mathrm{C}=\mathrm{N}-)$ group, and this electron density varies with the substituent's in the
TABLE 4: Polarization parameters and corresponding inhibition efficiency (IE) for the corrosion of the MS in $0.5 \mathrm{M} \mathrm{HCl}$ without and with addition of various concentrations of INIMH and INPMH at $30^{\circ} \mathrm{C}$.

\begin{tabular}{lcccc}
\hline Inhibitor & $\begin{array}{c}\text { Concentration } \\
(\mathrm{ppm})\end{array}$ & $\begin{array}{c}-E_{\text {corr }} \\
(\mathrm{mv})\end{array}$ & $\begin{array}{c}i_{\text {corr }} \\
\left(\mu \mathrm{A} \mathrm{cm}^{-2}\right)\end{array}$ & IE (\%) \\
\hline Blank & 0 & 508 & 2617.0 & - \\
\hline \multirow{4}{*}{ INIMH } & 200 & 468 & 687.0 & 73.74 \\
& 300 & 466 & 509.2 & 80.54 \\
& 400 & 458 & 498.8 & 80.94 \\
& 500 & 437 & 434.3 & 83.40 \\
\hline \multirow{3}{*}{ INPMH } & 200 & 485 & 871.5 & 66.69 \\
& 300 & 477 & 835.5 & 68.07 \\
& 400 & 465 & 526.8 & 79.87 \\
& 500 & 456 & 470.0 & 82.04 \\
\hline
\end{tabular}

inhibitor molecule. In both cases electron withdrawing and electron movement within the molecule is more facile. The imine nitrogen can donate the lone pair of electrons to the metal surface more easily and hence reduce the corrosion rate. The IE (\%) of INIMH was slightly higher than that of INPMH, which can probably be explained by the presence of one additional phenyl group in the molecule.

It is obvious from the polarization curves that both anodic as well as cathodic curves shift towards lower current density with the increasing concentration of the inhibitors. The lower the corrosion current density, the lesser will be the electron transfer in redox process; therefore the rate of corrosion reaction becomes slower. It was further noticed that both anodic and cathodic polarization profiles are influenced simultaneously almost to the same extent, suggesting the mixed action of the inhibitors. Usually a low current density and long anodization time present very good protection against corrosion due to the diminution of the porosity of the anodic films formed in the environmental condition.

3.6. Electrochemical Impedance Spectroscopy. The Nyquist plots for MS in $0.5 \mathrm{M} \mathrm{HCl}$ solution without and with different concentrations of INIMH and INPMH are shown in Figures 10(a) and 10(b), respectively. The Nyquist plots are regarded as one part of a semicircle mostly referred to as frequency dispersion which could be attributed to different physical 


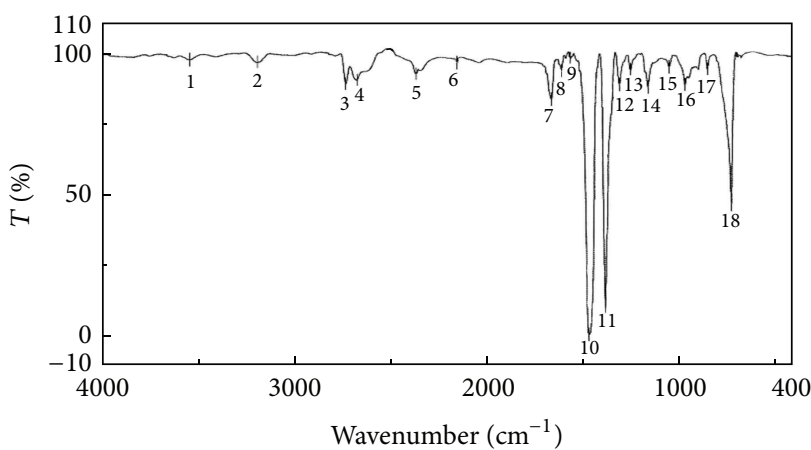

(a)

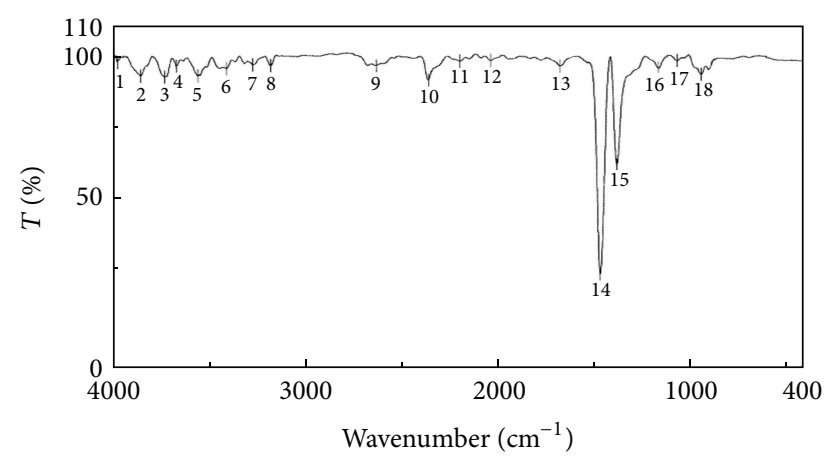

(b)

FIGURE 6: IR spectra of (a) INIMH and (b) scratched MS surface adsorbed INIMH film.

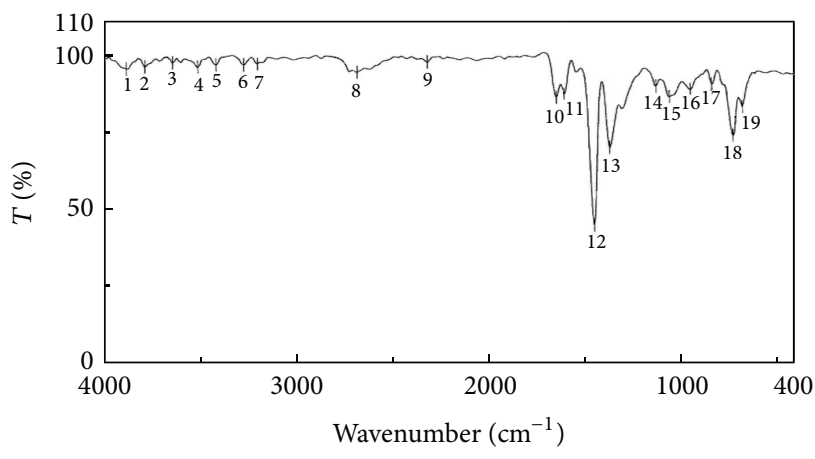

(a)

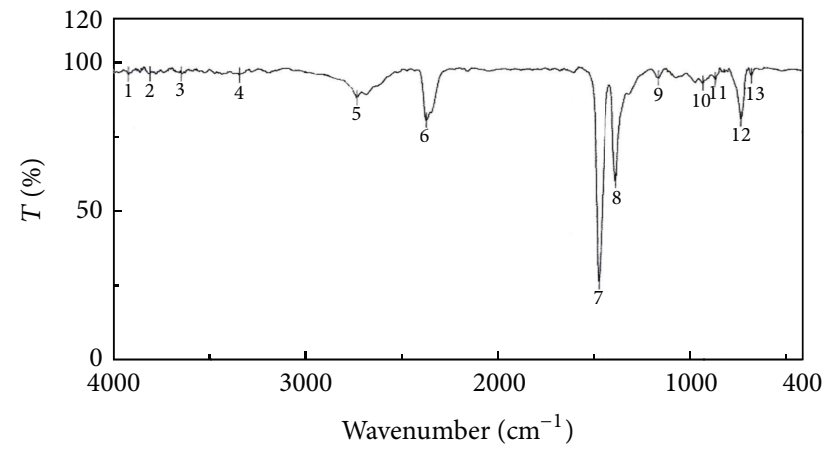

(b)

FIGURE 7: IR spectra of (a) INPMH and (b) scratched MS surface adsorbed INPMH film.<smiles>O=C(N/N=C/c1c[nH]c2ccccc12)c1ccncc1</smiles><smiles>O=C(N/N=C/c1ccc[nH]1)c1ccncc1</smiles>

FIGURE 8: Mechanism of interaction of INIMH and INPMH on MS surface.

phenomenon such as roughness, heterogeneities, impurities, grain boundaries, and distribution of the surface active sites [46]. The electrochemical impedance parameters derived from the Nyquist plots and the IE (\%) are listed in Table 5. From the plots it is clear that the impedance response of MS in uninhibited acid solution has significantly changed after the addition of inhibitors to the corrosive solution. This indicates that the impedance of the inhibited substrate has increased with increasing concentration of inhibitors. The measured impedance data are based on the equivalent circuit given in Figure 11, consisting of constant double layer capacitance $\left(C_{d l} C_{d l} C_{d l}\right)$ in parallel with polarization resistance $\left(R_{p}\right)$ which is in series with solution resistance $\left(R_{s}\right)$.

It was clear that $R_{p}$ values in the absence of the inhibitors are always lower than those in the presence of the inhibitors. 


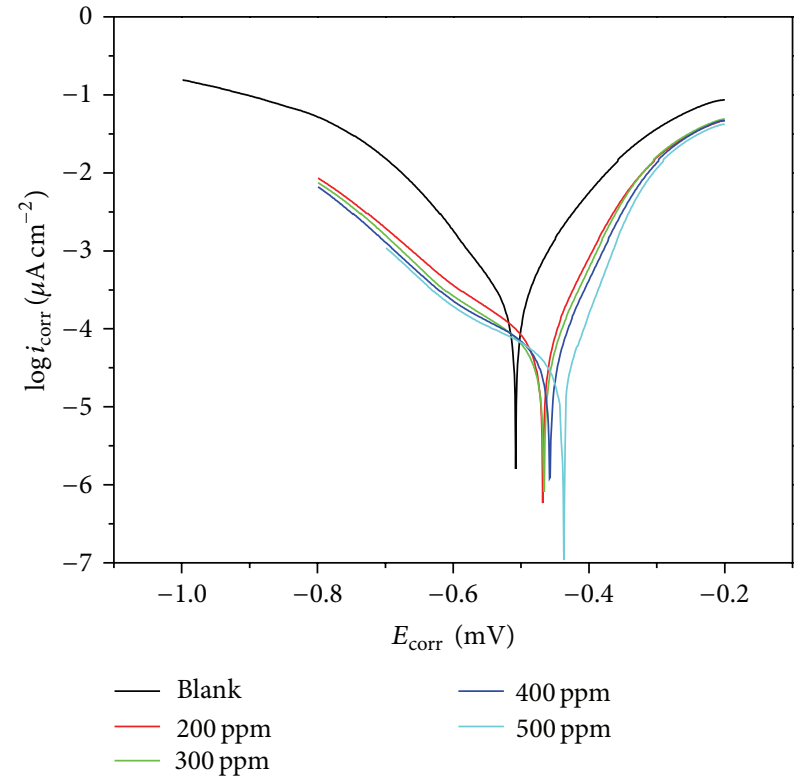

(a) INIMH

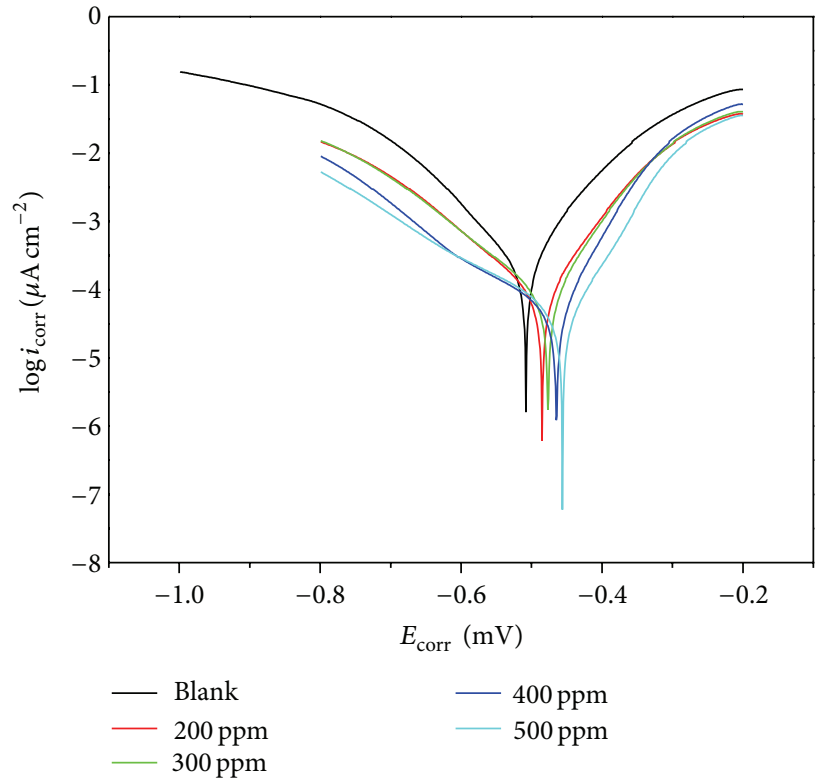

(b) INPMH

FIGURE 9: Polarization curves of MS in $0.5 \mathrm{M} \mathrm{HCl}$ in the presence of different concentrations of (a) INIMH and (b) INPMH.

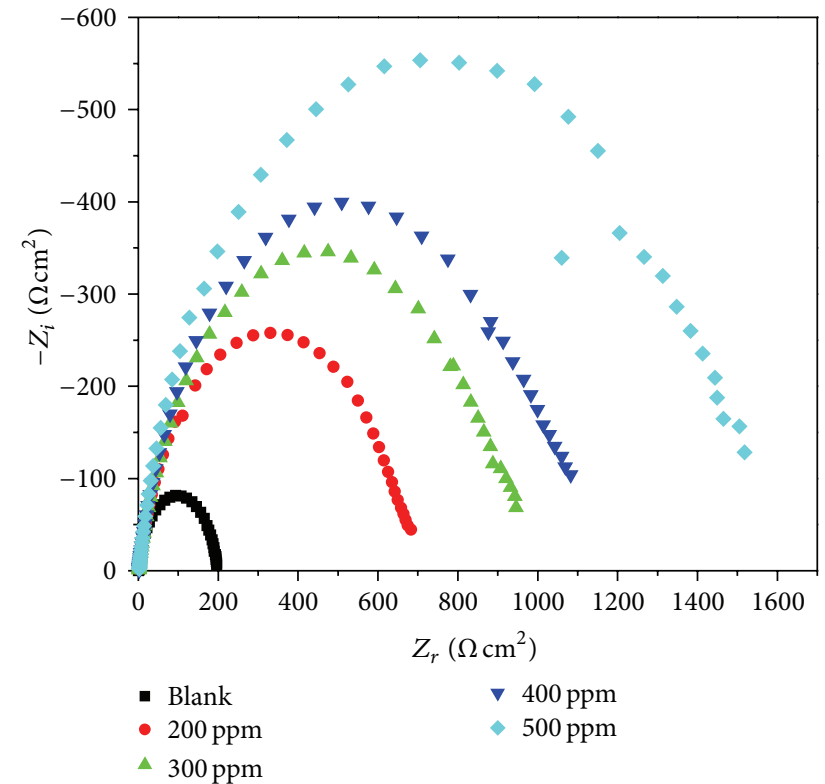

(a) INIMH

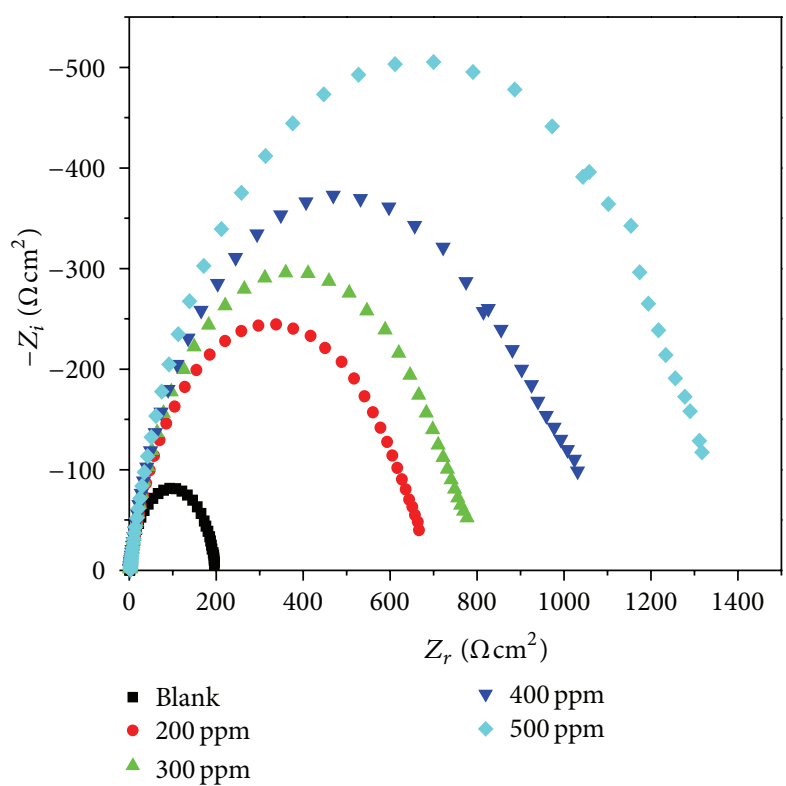

(b) INPMH

FIGURE 10: Nyquist plots for MS in $0.5 \mathrm{M} \mathrm{HCl}$ in the presence of different concentrations of (a) INIMH and (b) INPMH.

The increase in the $R_{p}$ values in the presence of different concentrations of INIMH and INPMH indicate reduction in the MS corrosion rate with the formation of adsorbed protective film on the metal-solution interface [47]. When the concentration was raised from 200 to $500 \mathrm{ppm}$, there was a gradual increase in the diameter of each semicircle of the Nyquist plot reflecting the increase of $R_{p}$ values from 177.5 to $1192 \Omega \mathrm{cm}^{2}$ for INIMH and from 177.5 to $1081 \Omega \mathrm{cm}^{2}$ for
INPMH. This indicates the adsorption of inhibitor molecules on the metal surface.

The double layer capacitance $\left(C_{d l}\right)$ values were decreased due to a decrease in local dielectric constant and/or an increase in the thickness of the electrical double layer, suggesting that the inhibitor molecules adsorb at the metalsolution interface $[48,49]$. The decrease in the surface area [50] and imperfections of the metal surface may also be the 


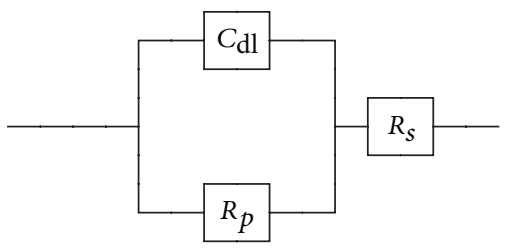

FIGURE 11: Equivalent circuit used to fit the impedance spectra.

TABLE 5: Impedance parameters for corrosion of $\mathrm{MS}$ in $0.5 \mathrm{M} \mathrm{HCl}$ in the absence and presence of different concentrations of INIMH and INPMH at $30^{\circ} \mathrm{C}$.

\begin{tabular}{lcccc}
\hline Inhibitors & $\begin{array}{c}\text { Concentration } \\
\text { (in ppm) }\end{array}$ & $R_{p}\left(\Omega \mathrm{cm}^{2}\right)$ & $C_{d l}\left(\mu \mathrm{F} \mathrm{Cm}^{-2}\right)$ & IE (\%) \\
\hline Blank & 0 & 177.5 & 149.60 & - \\
\hline \multirow{4}{*}{ INIMH } & 200 & 562.8 & 35.32 & 68.46 \\
& 300 & 759.3 & 27.97 & 76.62 \\
& 400 & 870.7 & 27.17 & 79.61 \\
& 500 & 1192.0 & 23.27 & 85.10 \\
\hline \multirow{4}{*}{ INPMH } & 200 & 537.5 & 39.51 & 66.97 \\
& 300 & 645.2 & 33.12 & 72.48 \\
& 400 & 817.2 & 29.62 & 78.27 \\
& 500 & 1081.0 & 27.69 & 83.58 \\
\hline
\end{tabular}

reason for decreasing of $C_{d l}$ values. Addition of inhibitors provided lower $C_{d l}$ values, because of the replacement of water molecules by inhibitor molecules at the electrode surface [51]. $C_{d l}$ values were found to be smaller in the presence of the inhibitors than in their absence, which results in the formation of a protective inhibitor adsorption layer on MS surface.

3.7. Mechanism of Inhibition. The inhibition effect of isoniazide derivatives towards the corrosion of mild steel in $0.5 \mathrm{M} \mathrm{HCl}$ solution may be attributed to the adsorption of these compounds at the metal-solution interface. The principal types of interaction between an organic inhibitor and metal surface are physisorption, chemisorption, or both. The adsorption of inhibitor is influenced by the nature of the metal, chemical structure of inhibitors, type of aggressive electrolyte, temperature, and the morphology of MS surface $[52,53]$. The values of inhibition efficiency depend essentially on the electron density at the active centre of the inhibitor molecule. The thermodynamic parameters showed that the adsorption of these inhibitors on the MS surface in $0.5 \mathrm{M} \mathrm{HCl}$ solution is both chemisorption and physisorption. Chemisorption of these inhibitors arises from the donoracceptor interactions between the free electron pairs of heteroatoms and pi-electrons of multiple bonds as well as phenyl group and vacant d-orbital's of iron [54].

In the case of INIMH, the inhibition effect was due to the interaction of pi-electrons of phenyl, pyrrole, and pyridine rings as well as the presence of electron donor atoms/groups $(\mathrm{N}, \mathrm{O}$, and $\mathrm{C}=\mathrm{N})$ through which it forms bonds with mild steel. In similar way, the inhibition effect in INPMH is due to pi-electrons of pyrrole and pyridine ring and, presence of $\mathrm{N}$, $\mathrm{O}$, and $\mathrm{C}=\mathrm{N}$, through which the inhibitors adsorb on the MS surface forming insoluble, stable, and uniform thin film. The highest inhibition efficiency of INIMH is due to the presence of additional pi-electrons in the phenyl group. The order of IE (\%) of these two inhibitors from mass loss, potentiodynamic polarization techniques, and EIS studies was found to be INIMH> INPMH.

3.8. EDX Analysis. EDX spectra were used to determine the elements present on MS surface before and after exposure to the inhibitor solution. The results are displayed in Figure 12. Figure 12(a) is the EDX spectrum of polished MS sample, and it is notable that the peak of oxygen is absent which confirms the absence of air-formed oxide film. However, for inhibited solutions, Figures 12(b) and 12(c) showed additional line characteristics for the existence of $\mathrm{N}$ and $\mathrm{O}$ (due to the $\mathrm{N}$ and $\mathrm{O}$ atoms of the INIMH and INPMH) in the EDX spectra. These data showed that the $\mathrm{N}$ and $\mathrm{O}$ atom of inhibitors has covered the MS electrode surface. These results confirm those obtained from IR and SEM measurements.

3.9. SEM Analysis. The inhibitive behaviour on MS due to corrosion process was confirmed by the SEM images of the polished and corroded MS surface in the absence and presence of inhibitors (Figures 13(a)-13(d)). SEM image of polished MS surface was given in Figure 13(a). Clear examination of SEM images reflects that the surface of the MS in the absence of the inhibitors was found to be corroded more, and the corrosion damages were observed in the form of large pits (Figure 13(b)). The MS specimens immersed in the inhibited solution were in much better condition with a smooth surface (Figures 13(c) and 13(d)). This shows that the inhibitor molecules hinder the dissolution of MS by forming surface adsorbed layer and thereby reducing the corrosion rate. It also confirms that the inhibitors effectively control the corrosion phenomenon by blocking the active corrosion causing sites on the MS surface.

\section{Conclusion}

The synthesized isonicotinic acid hydrazides were characterized by FTIR, ${ }^{1} \mathrm{H}-\mathrm{NMR}$, and mass spectral studies. It was found that the synthesized isonicotinic acid hydrazides are effective corrosion inhibitors. The results obtained from the mass loss measurements were in good agreement with those obtained from the potentiodynamic polarization and EIS methods. The data revealed that the inhibition action of the tested compounds was through both physisorption and chemisorption. The process obeyed the Langmuir adsorption isotherm, and the thermodynamic data indicated the spontaneous adsorption of inhibitors. IR spectral data revealed the interaction between inhibitor and MS surface. The corrosion protection action can be attributed to the presence of azomethine group $(\mathrm{HC}=\mathrm{N})$ in the inhibitor molecules. The results showed that the isonicotinic acid hydrazides are found to be good corrosion inhibitors for MS in $0.5 \mathrm{M} \mathrm{HCl}$ solution. The difference in the inhibitory property of the two inhibitors 


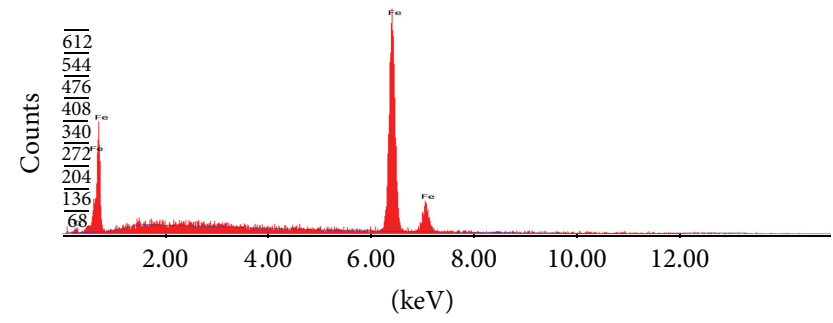

(a)

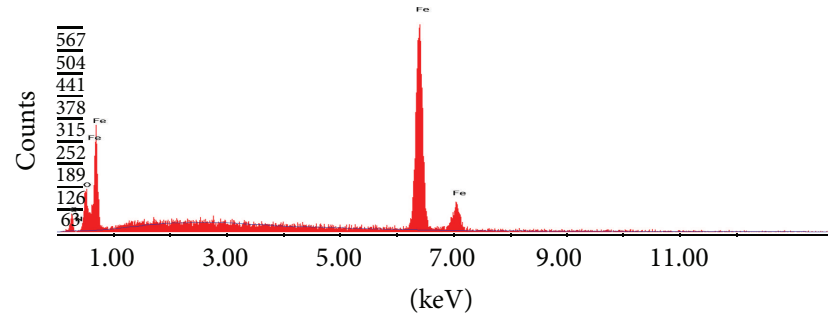

(b)

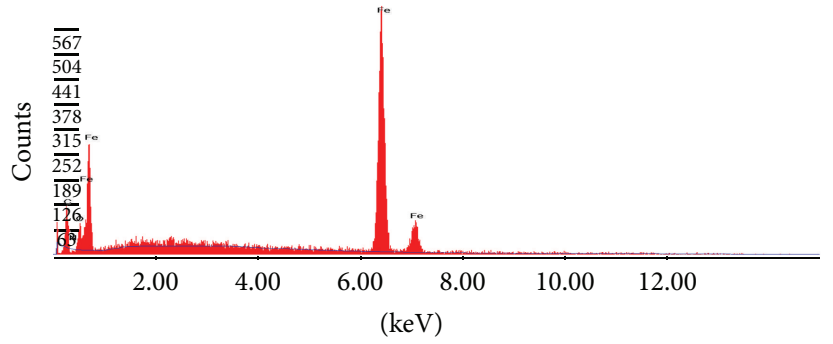

(c)

FIGURE 12: EDX images of (a) polished MS surface, (b) MS in 500 ppm INIMH, and (c) MS in 500 ppm INPMH.

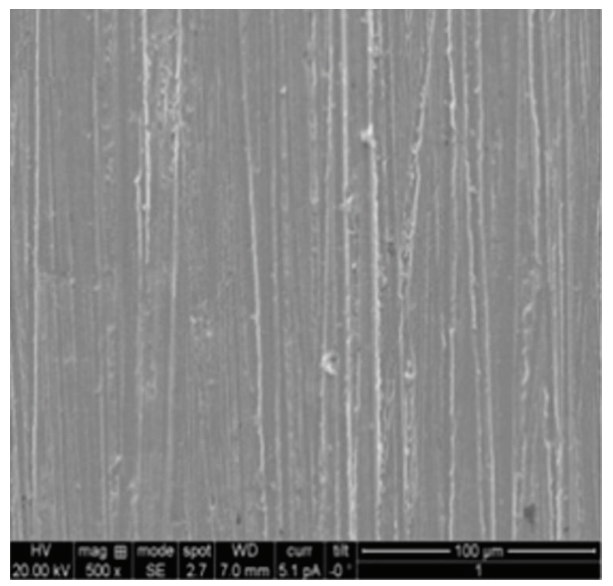

(a)

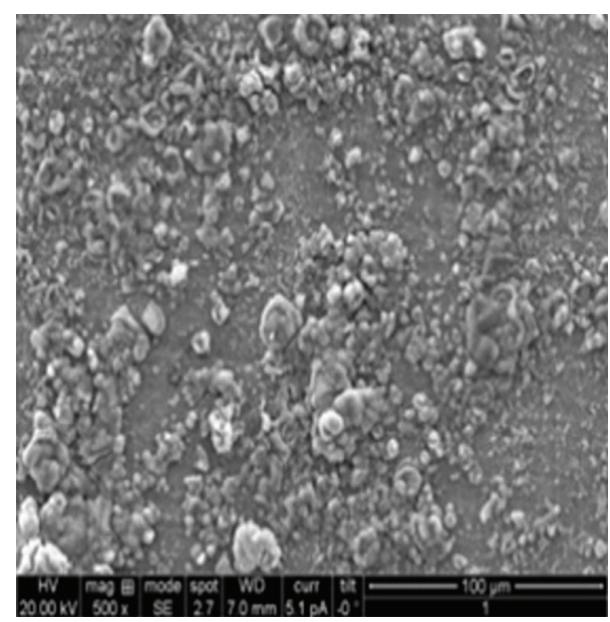

(c)

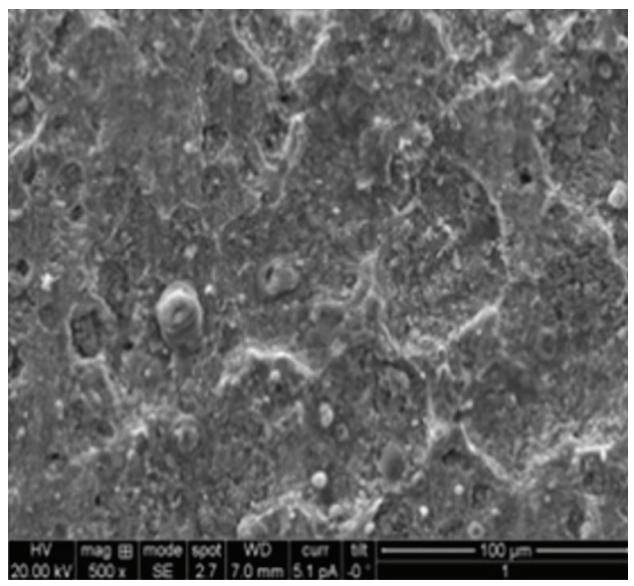

(b)

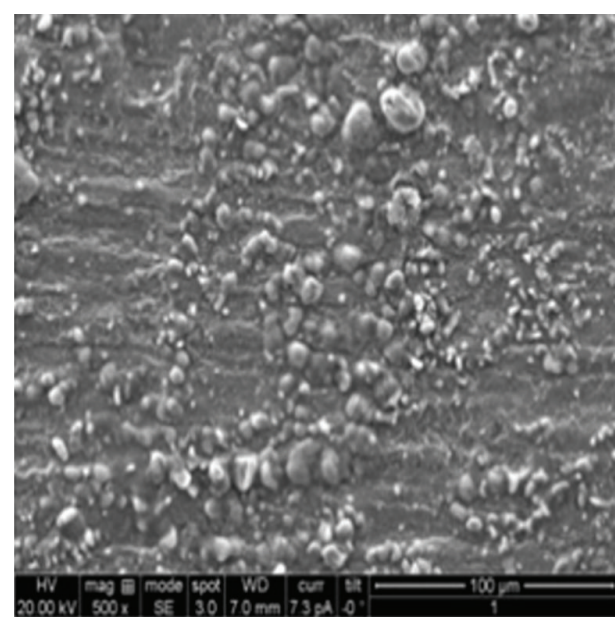

(d)

Figure 13: SEM images of (a) polished MS surface, (b) MS in $0.5 \mathrm{M} \mathrm{HCl}$, (c) MS in 500 ppm INIMH, and (d) MS in INPMH. 
is related to the difference in the availability of electrons in the inhibitor molecules and also presence of the extra phenyl group in INIMH. The SEM and EDX images showed the existence of protective film of inhibitors on MS surface.

\section{Acknowledgment}

One of the authors (M. P. Chakravarthy) is grateful to University of Mysore, Mysore, for awarding UGC fellowship to carry out the research work.

\section{References}

[1] V. P. Pavlov, P. Vanya, Y. Vanya, S. S. Ivanov, and S. S. Khlamkova, "Advantages of a technology for the hydride pickling of highalloy steels and alloys," Metallurgist, vol. 49, no. 7-8, Article ID UDC 661.968, pp. 293-295, 2005.

[2] S. Y. Cheng, C. T. Juan, S. L. Kuan, and W. T. Tsai, "Effect of annealing atmosphere on scale formation and pickling performance of 410 SS," Oxidation of Metals, vol. 60, no. 5-6, pp. 409-425, 2003.

[3] M. Bethencourt, F. J. Botana, J. J. Calvino, M. Marcos, and M. A. Rodríguez-Chacón, "Lanthanide compounds as environmentally-friendly corrosion inhibitors of aluminium alloys: a review," Corrosion Science, vol. 40, no. 11, pp. 1803-1819, 1998.

[4] M. A. Arenas, A. Conde, and J. J. De Damborenea, "Cerium: a suitable green corrosion inhibitor for tinplate," Corrosion Science, vol. 44, no. 3, pp. 511-520, 2002.

[5] E. Cano, P. Pinilla, J. L. Polo, and J. M. Bastidas, "Copper corrosion inhibition by fast green, fuchsin acid and basic compounds in citric acid solution," Materials and Corrosion, vol. 54, no. 4, pp. 222-228, 2003.

[6] D. Choi, Y. Kim, and J. Kim, "Development of a blended corrosion, scale, and microorganism inhibitor for open recirculating cooling systems," Werkstoffe und Korrosion, vol. 52, no. 9, pp. 697-704, 2001.

[7] G. Moretti, F. Guidi, and G. Grion, "Tryptamine as a green iron corrosion inhibitor in $0.5 \mathrm{M}$ deaerated sulphuric acid," Corrosion Science, vol. 46, no. 2, pp. 387-403, 2004.

[8] S. A. Abd El-Maksoud, "The effect of organic compounds on the electrochemical behaviour of steel in acidic media-a review," International Journal of Electrochemical Science, vol. 3, pp. 528$555,2008$.

[9] G. Trabanelli, "Inhibitors. An old remedy for a new challenge," Corrosion, vol. 47, no. 6, pp. 410-419, 1991.

[10] S. E. Nataraja, T. V. Venkatesha, K. Manjunatha, B. Poojary, M. K. Pavithra, and H. C. Tandon, "Inhibition of the corrosion of steel in hydrochloric acid solution by some organic molecules containing the methylthiophenyl moiety," Corrosion Science, vol. 53, no. 8, pp. 2651-2659, 2011.

[11] L. Wang, "Inhibition of mild steel corrosion in phosphoric acid solution by triazole derivatives," Corrosion Science, vol. 48, no. 3, pp. 608-616, 2006.

[12] M. Bouklah, N. Benchat, A. Aouniti et al., "Effect of the substitution of an oxygen atom by sulphur in a pyridazinic molecule towards inhibition of corrosion of steel in $0.5 \mathrm{M}$ $\mathrm{H}_{2} \mathrm{SO}_{4}$ medium," Progress in Organic Coatings, vol. 51, no. 2, pp. 118-124, 2004.

[13] H. Wang, R. Liu, and J. Xin, "Inhibiting effects of some mercapto-triazole derivatives on the corrosion of mild steel in
1.0 M HC1 medium," Corrosion Science, vol. 46, no. 10, pp. 24552466, 2004.

[14] M. Karakuş, M. Şahin, and S. Bilgiç, "An investigation on the inhibition effects of some new dithiophosphonic acid monoesthers on the corrosion of the steel in $1 \mathrm{M} \mathrm{HCl}$ medium," Materials Chemistry and Physics, vol. 92, no. 2-3, pp. 565-571, 2005.

[15] A. Rahim, E. Rocca, J. Steinmetz, M. J. Kassim, R. Adnan, and M. Sani Ibrahim, "Mangrove tannins and their flavanoid monomers as alternative steel corrosion inhibitors in acidic medium," Corrosion Science, vol. 49, no. 2, pp. 402-417, 2007.

[16] W. Li, Q. He, C. Pei, and B. Hou, "Experimental and theoretical investigation of the adsorption behaviour of new triazole derivatives as inhibitors for mild steel corrosion in acid media," Electrochimica Acta, vol. 52, no. 22, pp. 6386-6394, 2007.

[17] S. Sankarapapavinasam, F. Pushpanaden, and M. F. Ahmed, "Inhibition of mild steel corrosion in phosphoric acid solution by triazole derivatives," Corrosion Science, vol. 48, no. 3, pp. 608616, 2006.

[18] S. A. M. Refaey, F. Taha, and A. M. A. El-Malak, "Inhibition of stainless steel pitting corrosion in acidic medium by 2mercaptobenzoxazole," Applied Surface Science, vol. 236, no. 1, pp. 175-185, 2004.

[19] M. A. Quraishi and H. K. Sharma, "Thiazoles as corrosion inhibitors for mild steel in formic and acetic acid solutions," Journal of Applied Electrochemistry, vol. 35, no. 1, pp. 33-39, 2005.

[20] M. A. Quraishi, M. A. W. Khan, M. Ajmal, S. Muralidharan, and S. V. Iyer, "Influence of heterocyclic anils on corrosion inhibition and hydrogen permeation through mild steel in acid chloride environments," Corrosion, vol. 53, no. 6, pp. 475-480, 1997.

[21] S. D. Shetty, P. Shetty, and H. V. S. Nayak, "The inhibition action of N-furfuryl-N/-phenyl thiourea on the corrosion of mild steel in acid media," Journal of the Serbian Chemical Society, vol. 71, no. 10, pp. 1073-1082, 2006.

[22] G. Bereket, E. Hür, and C. Öretir, "Quantum chemical studies on some imidazole derivatives as corrosion inhibitors for iron in acidic medium," Journal of Molecular Structure, vol. 578, pp. 79-88, 2002.

[23] O. I. Sizaya and A. P. Andrushko, "On the use of triazines as inhibitors of steel corrosion," Protection of Metals, vol. 40, no. 2, pp. 164-168, 2004.

[24] L. Herrag, A. Chetouani, S. Elkadiri, B. Hammouti, and A. Aouniti, "Pyrazole derivatives as corrosion inhibitors for steel in hydrochloric acid," Portugaliae Electrochimica Acta, vol. 26, no. 2, pp. 211-220, 2008.

[25] K. F. Khaled and N. A. Al-Mobarak, "A predictive model for corrosion inhibition of mild steel by thiophene and its derivatives using artificial neural network," International Journal of Electrochemical Science, vol. 7, no. 2, pp. 1045-1059, 2012.

[26] A. Zarrouk, A. Dafali, B. Hammouti, H. Zarrok, S. Boukhris, and M. Zertoubi, "Synthesis, characterization and comparative study of functionalized quinoxaline derivatives towards corrosion of copper in nitric acid medium," International Journal of Electrochemical Science, vol. 5, no. 1, pp. 46-55, 2010.

[27] F. Bentiss, M. Lagrenee, M. Traisnel, and J. C. Hornez, "The corrosion inhibition of mild steel in acidic media by a new triazole derivative," Corrosion Science, vol. 41, no. 4, pp. 789803, 1999. 
[28] A. Singh, A. K. Singh, and M. A. Quraishi, "Dapsone: a novel corrosion inhibitor for mild steel in acid media," The Open Electrochemistry Journal, vol. 2, pp. 43-51, 2010.

[29] M. A. Quraishi and H. K. Sharma, "4-amino-3-butyl-5mercapto-1,2,4-triazole: a new corrosion inhibitor for mild steel in sulphuric acid," Materials Chemistry and Physics, vol. 78, no. 1, pp. 18-21, 2003.

[30] T. Poornima, J. Nayak, and A. N. Shetty, "Corrosion inhibition of the annealed $18 \mathrm{Ni} 250$ grade maraging steel in $0.67 \mathrm{M}$ phosphoric acid by by 3,4-dimethoxybenzaldehydethiosemicarbazone," Chemical Sciences Journal, vol. 69, pp. 1-14, 2012.

[31] I. N. Putilova, S. A. Blazin, and U. P. Baranik, Metal Corrosion Inhibitors, Pergamon Press, New York, NY, USA, 1960.

[32] M. Abdallah, E. A. Helal, and A. S. Fouda, "Aminopyrimidine derivatives as inhibitors for corrosion of 1018 carbon steel in nitric acid solution," Corrosion Science, vol. 48, no. 7, pp. 16391654, 2006.

[33] S. S. Abd El-Rehim, S. A. M. Refaey, F. Taha, M. B. Saleh, and R. A. Ahmed, "Corrosion inhibition of mild steel in acidic medium using 2-amino thiophenol and 2-cyanomethyl benzothiazole," Journal of Applied Electrochemistry, vol. 31, no. 4, pp. 429-435, 2001.

[34] A. Yurt, A. Balaban, S. U. Kandemir, G. Bereket, and B. Erk, "Investigation on some Schiff bases as $\mathrm{HCl}$ corrosion inhibitors for carbon steel," Materials Chemistry and Physics, vol. 85, no. 2-3, pp. 420-426, 2004.

[35] L. Tang, X. Li, Y. Si, G. Mu, and G. Liu, "The synergistic inhibition between 8-hydroxyquinoline and chloride ion for the corrosion of cold rolled steel in $0.5 \mathrm{M}$ sulfuric acid," Materials Chemistry and Physics, vol. 95, no. 1, pp. 29-38, 2006.

[36] A. K. Bhattacharya, T. K. Naiya, S. N. Mandal, and S. K. Das, "Adsorption, kinetics and equilibrium studies on removal of $\mathrm{Cr}(\mathrm{VI})$ from aqueous solutions using different low-cost adsorbents," Chemical Engineering Journal, vol. 137, no. 3, pp. 529-541, 2008.

[37] S. A. M. Refaey, F. Taha, and A. M. Abd El-Malak, "Corrosion and inhibition of $316 \mathrm{~L}$ stainless steel in neutral medium by 2mercaptobenzimidazole," International Journal of Electrochemical Science, vol. 1, pp. 80-91, 2006.

[38] G. K. Gomma and M. H. Wahdan, "Schiff bases as corrosion inhibitors for aluminium in hydrochloric acid solution," Materials Chemistry \& Physics, vol. 39, no. 3, pp. 209-213, 1995.

[39] B. V. Savithri and S. M. Mayanna, "Tetrabutyl ammonium iodide, cetyl pyridinium bromide and cetyl trimethyl ammonium bromide as corrosion inhibitors for mild steel in sulphuric acid," Indian Journal of Chemical Technology, vol. 3, no. 5, pp. 256-258, 1996.

[40] M. Elayyachy, A. El Idrissi, and B. Hammouti, "New thiocompounds as corrosion inhibitor for steel in $1 \mathrm{M} \mathrm{HCl,"} \mathrm{Cor-}$ rosion Science, vol. 48, no. 9, pp. 2470-2479, 2006.

[41] F. M. Bayoumi and W. A. Ghanem, "Corrosion inhibition of mild steel using naphthalene disulfonic acid," Materials Letters, vol. 59, no. 29-30, pp. 3806-3809, 2005.

[42] M. A. Amin, "Weight loss, polarization, electrochemical impedance spectroscopy, SEM and EDX studies of the corrosion inhibition of copper in aerated $\mathrm{NaCl}$ solutions," Journal of Applied Electrochemistry, vol. 36, no. 2, pp. 215-226, 2006.

[43] O. L. Riggs Jr., Corrosion Inhibitors, NACE, Houston, Tex, USA, 2nd edition, 1973.

[44] E. S. Ferreira, C. Giacomelli, F. C. Giacomelli, and A. Spinelli, "Evaluation of the inhibitor effect of L-ascorbic acid on the corrosion of mild steel," Materials Chemistry and Physics, vol. 83, no. 1, pp. 129-134, 2004.

[45] A. Y. Musa, A. A. H. Kadhum, A. B. Mohamad, M. S. Takriff, A. R. Daud, and S. K. Kamarudin, "On the inhibition of mild steel corrosion by 4-amino-5-phenyl-4H-1, 2, 4-trizole-3-thiol," Corrosion Science, vol. 52, no. 2, pp. 526-533, 2010.

[46] K. Jüttner, "Electrochemical impedance spectroscopy (EIS) of corrosion processes on inhomogeneous surfaces," Electrochimica Acta, vol. 35, no. 10, pp. 1501-1508, 1990.

[47] S. Ningshen, U. Kamachi Mudali, P. Mukherjee, P. Barat, and B. Raj, "Oxygen ion irradiation effect on corrosion behavior of titanium in nitric acid medium," Journal of Nuclear Materials, vol. 408, no. 1, pp. 1-6, 2011.

[48] M. Lebrini, F. Bentiss, H. Vezin, and M. Lagrenée, "The inhibition of mild steel corrosion in acidic solutions by 2,5bis(4-pyridyl)-1,3,4-thiadiazole: structure-activity correlation," Corrosion Science, vol. 48, no. 5, pp. 1279-1291, 2006.

[49] S. K. Shukla and M. A. Quraishi, "The effects of pharmaceutically active compound doxycycline on the corrosion of mild steel in hydrochloric acid solution," Corrosion Science, vol. 52, no. 2, pp. 314-321, 2010.

[50] F. Bentiss, M. Traisnel, and M. Lagrenee, “The substituted 1,3,4oxadiazoles: a new class of corrosion inhibitors of mild steel in acidic media," Corrosion Science, vol. 42, no. 1, pp. 127-146, 2000.

[51] K. Parameswari, S. Chitra, C. Nusrath Unnisa, and A. Selvaraj, "Effect of azlactones on corrosion inhibition of mild steel in acid medium," Journal of Applied Sciences Research, vol. 6, no. 8, pp. 1100-1110, 2010.

[52] S. Aloui, I. Forsal, M. Sfaira et al., "New mechanism synthesis of 1,4-benzothiazine and its inhibition performance on mild steel in hydrochloric acid," Portugaliae Electrochimica Acta, vol. 27, no. 5, pp. 599-613, 2009.

[53] I. Zaafarany, "Phenyl phthalimide as corrosion inhibitor for corrosion of C-Steel in sulphuric acid solution," Portugaliae Electrochimica Acta, vol. 27, no. 5, pp. 631-643, 2009.

[54] I. Ahamad and M. A. Quraishi, "Bis (benzimidazol-2-yl) disulphide: an efficient water soluble inhibitor for corrosion of mild steel in acid media," Corrosion Science, vol. 51, no. 9, pp. 20062013, 2009. 

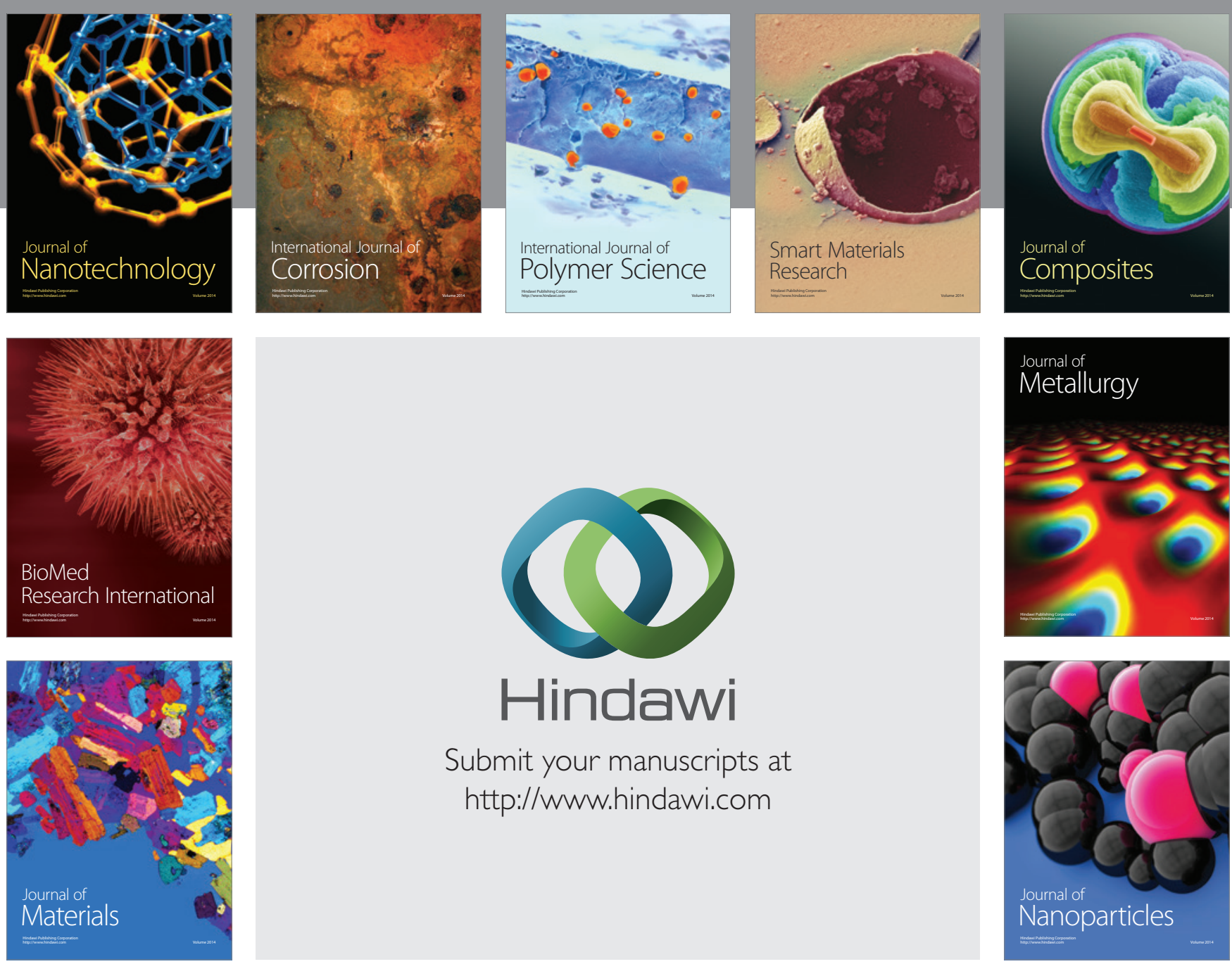

Submit your manuscripts at http://www.hindawi.com
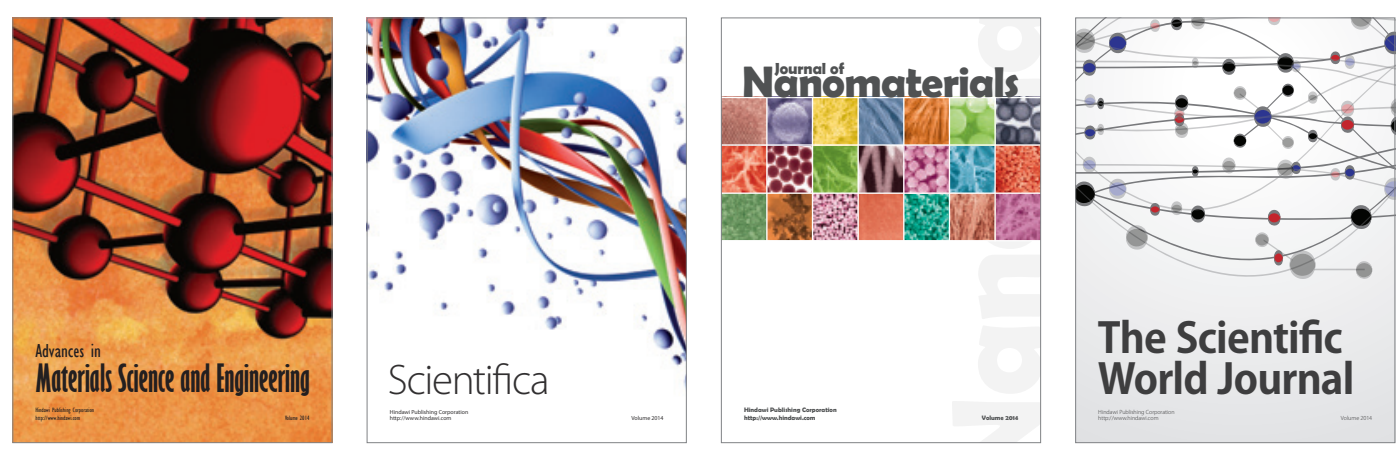

\section{The Scientific World Journal}
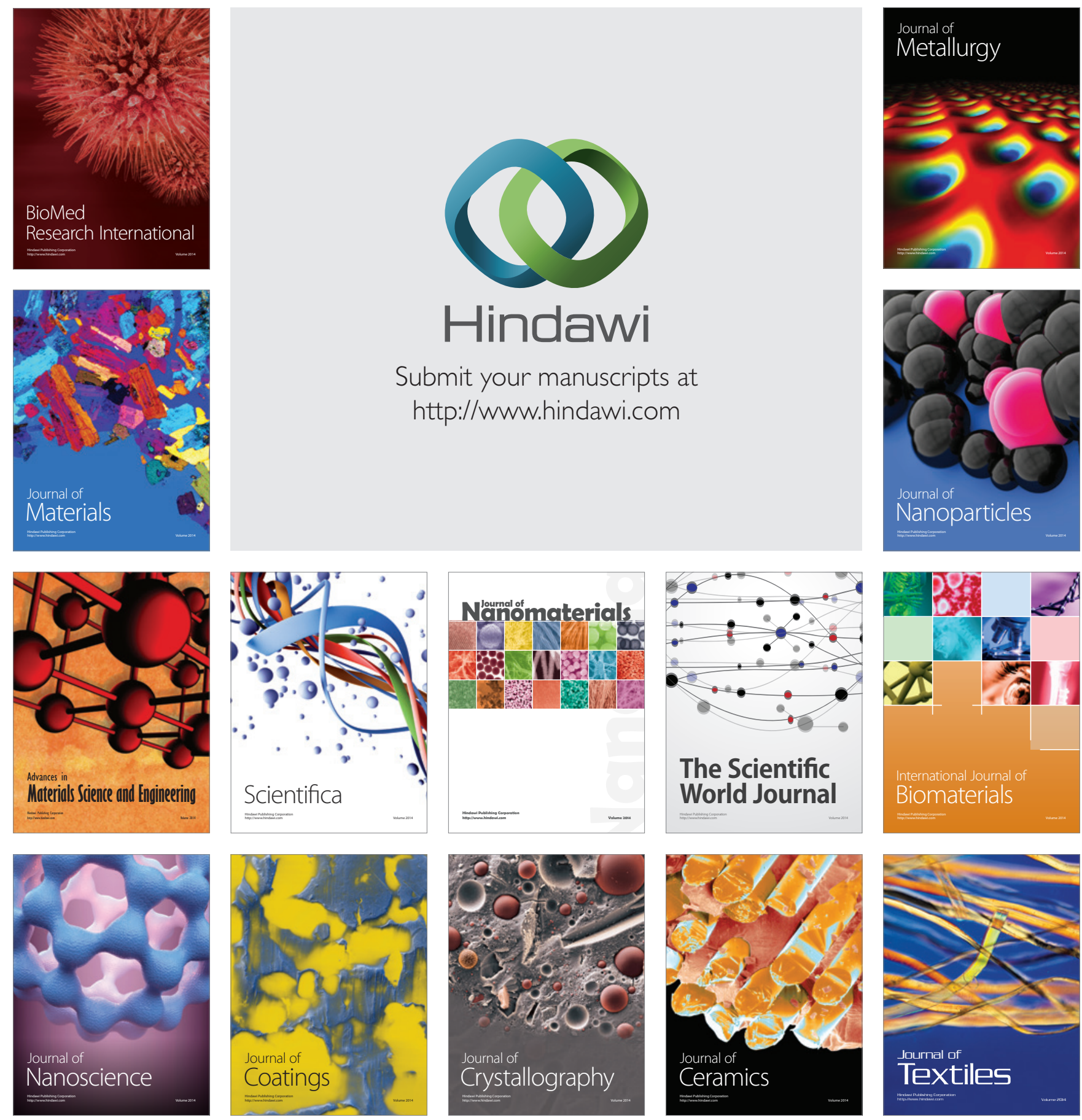